\title{
Gender differences in left ventricle geometry and function in patients undergoing balloon dilatation of the aortic valve for isolated aortic stenosis
}

Pamela S Douglas, Catherine M Otto, Mary C Mickel, Arthur Labovitz, Cheryl L Reid, Kathryn B Davis for the NHLBI Balloon Valvuloplasty Registry

\begin{abstract}
Background-Gender differences in cardiac size have been described in normal humans and animals and in response to pressure overload. To examine the influence of gender on the left ventricular response to pressure overload, clinical, haemodynamic, and echocardiographic data were analysed in the 232 adults with isolated aortic stenosis enrolled in the Balloon Valvuloplasty Registry.
\end{abstract}

Methods and results-There were 92 men (mean (SD) age 75 (11) years) and 140 women (79 (9) years; $P=0.002$ ). Women had similar symptoms (New York Heart Association class) but lower overall functional status than men $(P=0.008)$. Catheterisation data showed similar valve area indices (mean (SD)) $(0.30$ $(0.09)$ in men and $0.31(0.13) \mathrm{cm} / \mathrm{m}^{2}$ in women) but higher peak and mean gradients in women (peak 74 (30) $v 63$ (22) $\mathrm{mm}$ Hg; mean 61 (21) $v 54$ (18) $\mathrm{mm}$ Hg; both $P \leqslant 0.01)$. On $M$ mode echocardiography women had greater septal and posterior wall thicknesses but similar cavity diameter, after normalising dimensions to body surface area, resulting in higher relative wall thickness $(0.60$ $(0.20) v 0.50(0.15) ; P=0.0002)$. Left ventricular mass index was similar in women and men (166 (59) $v 159$ (50) $\mathrm{gm} / \mathrm{m}^{2}$ respectively), however, the prevalence of left ventricular hypertrophy according to sex specific criteria was $54 \%$ in men and $81 \%$ in women $(P=0.0001)$. Multiple logistic regression models that adjusted for age, functional status, fractional shortening, and left ventricular systolic pressure found the presence or absence of hypertrophy to be independently associated with gender $(P \leqslant 0.002)$. Left ventricular systolic function tended to be better in women, who had a higher cardiac index $\left(2.5(0.8) v 2.3(0.6) 1 / \mathrm{min} / \mathrm{m}^{2}\right.$; $\mathbf{P}=0.01)$, left ventricular peak systolic pressure (211 (36) $v 192$ (35) $\mathrm{mm} \mathrm{Hg;} \mathrm{P} \mathrm{=}$ 0.0001 ), and echo fractional shortening (32 (13) $v 28$ (12)\%; $P=0.05)$; however, these differences were reduced when patients with regional wall motion abnormalities were excluded.

Conclusions-In this population of elderly patients undergoing balloon dilatation of isolated aortic stenosis, left ventricular chamber geometry was different in men and women. Because this was a selected population, gender should be further evaluated as a possible determinant of the cardiac adaptation to chronic pressure overload.

(Br Heart F 1995;73:548-554)

Keywords: Left ventricular mass; relative wall thickness; aortic stenosis; gender

Left ventricular hypertrophy in aortic stenosis has long been of interest to both clinicians and physiologists as an index of the left ventricle's response to pressure overload and of the intricate interactions between haemodynamic load, cardiac remodelling, and ventricular performance. Because afterload also limits ventricular ejection, the success of the hypertrophic process can be judged by the extent to which stress is normalised. If stress is not reduced and the extent of hypertrophy is therefore inadequate, afterload excess may result, depressing pump performance.

Observations in both animals and humans suggest that cardiac size is different in the two sexes. Normal values for left ventricular mass are higher in men irrespective of whether they are unnormalised or normalised to body surface area or to height. ${ }^{12}$ Gender differences in the myocardium's ability to hypertrophy have not been extensively examined in humans, but several studies suggest that such differences may indeed exist. Data from healthy individuals show a greater increase in left ventricular mass with aging in women ${ }^{34}$; several studies of hypertensive patients have shown a higher prevalence of hypertrophy in women. ${ }^{56}$ Carroll et al found a higher relative wall thickness and better preservation of systolic left ventricular function in elderly women with aortic stenosis. ${ }^{7}$ Similar data were presented by Villari et $a l^{8}$ and by Aurigemma et al. ${ }^{9}$ These data in humans are consistent with animal studies showing lower left ventricular mass in normal female rats, ${ }^{10} 11$ but a greater degree of hypertrophy in response to both physiological ${ }^{12}$ and pathological stimuli (pressure overload in spontaneously hypertensive rats). ${ }^{13}$

In the present study we examined gender differences in the response to pressure overload caused by stenosis of the aortic valve in adults undergoing balloon dilatation of the aortic valve. We hypothesised that both chamber geometry and left ventricular function may be different in men and women undergoing balloon dilatation of the aortic valve for stenosis. 


\section{Patients and methods \\ STUDY POPULATION}

We screened all 772 adults enrolled in the Balloon Valvuloplasty Registry who had balloon dilatation of the aortic valve at 24 medical centres between 1 November 1987 and 31 October 1989. Patients were chosen for balloon dilatation, valve replacement, or no intervention on the basis of referral by their physician. Each patient gave informed consent and the study protocol was approved by each institution's review board. Patients were excluded if any of the following were present or if data on the presence or absence of the condition were missing: coronary artery disease $(\geqslant 70 \%$ diameter stenosis of at least one coronary vessel), echocardiographic evidence of severe mitral regurgitation or severe aortic regurgitation, or any evidence of mitral stenosis. The rates of exclusion were similar in men and women except for documented coronary artery disease, which was more common in men $(P=0.01)$, and mitral stenosis, which was more common in women $(P=0.004)$. The remaining 232 patients formed the study population. There were 92 men $(28 \%$ of the men in the original cohort) and 140 women $(31 \%$ of the women in the original cohort (table 1).

\section{FUNCTIONAL STATUS}

Overall symptoms and functional status were assessed by New York Heart Association score and by a 100 point score based on nine activities of daily living as described by Jette et $a l .^{14}$

\section{ECHOCARDIOGRAPHY}

Echocardiographic data were recorded and analysed at each medical centre according to strictly defined standards agreed to by each echocardiographer. $M$ mode echocardiography was used to measure left ventricular dimensions at end systole and end diastole according to standard American Society of Echocardiography methods. ${ }^{15}$ Left ventricular mass was calculated according to the cube formula such that left ventricular mass equals $0.80 \times 1.05 \times\left[\left(\mathrm{ST}+\mathrm{PWT}+\mathrm{LVID}^{3}\right.\right.$ - LVID $\left.^{3}\right)$, where ST is septal thickness, PWT is posterior wall thickness, and LVID is left ventricular internal dimension. The constant 0.80 is an anatomically validated regres-

Table 1 Reasons for exclusion of patients from study

\begin{tabular}{llcl}
\hline & Men (\%) & Women (\%) & P Value \\
\hline Total aortic BVR patients & 325 & 447 & \\
$\begin{array}{l}\text { Coronary artery disease: } \\
\quad 70 \% \text { stenosis }\end{array}$ & $134(50)$ & $138(40)$ & 0.01 \\
$\quad$ >70\% stenosis or data missing & $190(58)$ & $238(53)$ & 0.15 \\
$\begin{array}{l}\text { Mitral regurgitation: } \\
\quad \text { Severe }\end{array}$ & $20(7)$ & $32(8)$ & 0.61 \\
$\quad$ Severe or data missing & $73(22)$ & $100(22)$ & 0.98 \\
Aortic regurgitation: & $0(0)$ & $3(1)$ & 0.27 \\
$\quad$ Severe & $44(14)$ & $69(15)$ & 0.46 \\
$\quad$ Severe or data missing & $34(11)$ & $78(18)$ & 0.006 \\
$\quad$ Mitral stenosis: & $39(12)$ & $89(20)$ & 0.004 \\
$\quad$ Present or data missing & $92(28)$ & $140(31)$ & \\
Study population & & & \\
(remaining patients) & &
\end{tabular}

BVR, balloon aortic valvuloplasty registry. sion correction for the overestimation of left ventricular mass resulting from the use of American Society of Echocardiographic measures (rather than Penn Convention) for cardiac dimensions. ${ }^{16}$ Relative wall thickness was calculated as two times the diastolic posterior wall thickness divided by cavity diameter.

The prevalence of left ventricular hypertrophy was judged according to three criteria developed by the Framingham Heart Study: uncorrected mass, for which the upper limit of normal for men is $294 \mathrm{~g}$ and for women 198 $\mathrm{g}$; left ventricular mass indexed to body surface area, for which the upper limit of normal is $150 \mathrm{gm} / \mathrm{m}^{2}$ for men and $120 \mathrm{gm} / \mathrm{m}^{2}$ for women; and left ventricular mass indexed to height, for which the upper limit of normal is $163 \mathrm{~g} / \mathrm{m}$ for men and $121 \mathrm{~g} / \mathrm{m}$ for women. ${ }^{1}$

Systolic function was assessed in several ways. Overall systolic function was qualitatively assessed on cross sectional echocardiography by experienced observers as normal or enhanced or mildly, moderately, or severely reduced. Fractional shortening was calculated from $M$ mode echocardiography as end diastolic minus end systolic cavity dimensions divided by end diastolic dimension, multiplied by 100 . A quantitative score was used to judge fractional shortening by category as follows: reduced fractional shortening, $\leqslant 28 \%$; normal, between 28 and $40 \%$; and hyperdynamic, $\geqslant 40 \%$. The presence or absence of segmental wall motion abnormalities was noted on cross sectional echocardiography. Finally, all data were analysed in the patient group as a whole, as well as only in those without regional wall motion abnormalities.

Aortic and mitral regurgitation were evaluated by conventional pulsed and/or colour Doppler methods with grading of severity (none, mild, or moderate) according to standard criteria. ${ }^{17}$ The peak velocity of the aortic stenotic jet was recorded with continuous wave Doppler in the acoustic window yielding the highest value. The mean pressure gradient across the aortic valve was determined by averaging the instantaneous gradient throughout systolic ejection and applying the modified Bernoulli equation $\left(\Delta \mathrm{P}=4 \mathrm{~V}^{2}\right)$. In addition, left ventricular outflow tract velocity was recorded using pulsed Doppler technique from the apical approach and the valve area index calculated according to the continuity equation. ${ }^{17}$ Peak valve resistance was calculated as AV Vmax $\div$ LVOT cross sectional area $\times$ LVOT Vmax.

\section{CATHETERISATION DATA}

Left ventricular peak pressures during systole and at end diastole and the peak and mean gradients across the aortic valve were measured in standard fashion. The valve area index was calculated immediately before balloon dilatation by either the Gorlin or Hakki formulas using Fick, thermodilution, or green dye cardiac output.

STATISTICAL METHODS

Continuous variables are expressed as mean (SD) deviation and categorical variables are 
Table 2 Demographic data and outcome

\begin{tabular}{|c|c|c|c|c|c|c|}
\hline & \multicolumn{3}{|l|}{ All patients } & \multicolumn{3}{|c|}{ Excluding patients with wall motion abnormalities } \\
\hline & Men & Women & $P$ Value & Men & Women & $P$ Value \\
\hline $\mathbf{N}$ & 92 & 140 & & 61 & 108 & \\
\hline Age & $75(11)$ & $79(9)$ & 0.002 & $75(11)$ & $79(9)$ & 0.01 \\
\hline BSA & $1.86(0.18)$ & $1.60(0.17)$ & 0.0001 & $1.88(0.17)$ & $1.59(0.17)$ & 0.0001 \\
\hline NYHA class III or IV & $63(70 \%)$ & $109(78 \%)$ & $0 \cdot 18$ & $39(65 \%)$ & $82(76 \%)$ & $0 \cdot 13$ \\
\hline Overall functional status & $56(26)$ & $47(26)$ & 0.008 & $62(26)$ & $47(26)$ & 0.002 \\
\hline CHF & $85(92 \%)$ & $128(91 \%)$ & 0.79 & $57(93 \%)$ & $97(90 \%)$ & 0.43 \\
\hline Syncope & $31(34 \%)$ & $56(40 \%)$ & 0.33 & $17(28 \%)$ & $47(44 \%)$ & 0.04 \\
\hline Atrial fibrillation & $15(16 \%)$ & $28(20 \%)$ & 0.48 & $12(20 \%)$ & $20(19 \%)$ & 0.85 \\
\hline 30 day mortality & $11(12 \%)$ & $7(5 \%)$ & 0.06 & $4(7 \%)$ & $5(5 \%)$ & $0 \cdot 60$ \\
\hline
\end{tabular}

CHF, congestive heart failure; NYHA, New York Heart Association.

given as number (per cent). Missing data resulted in reduced sample sizes for many variables. If $\geqslant 5 \%$ of the values are unknown, the sample size is indicated.

Values for men and women were compared by the two sample $t$ test for continuous variables, using a pooled estimate of variance if the variances were not significantly different at the 0.05 level by the $\mathrm{F}$ test. Binary variables were compared by the $\chi^{2}$ test or by Fisher's exact test, with the test for trend used for ordered categorical data.

Multiple logistic and linear regression models adjusting for age, left ventricular systolic pressure, fractional shortening, and functional status were used in analysing the association between gender and left ventricular hypertrophy or relative wall thickness. ${ }^{18}$

The relations between left ventricular peak systolic pressure and fractional shortening or left ventricular systolic function score were examined by linear regression. ${ }^{18}$ Initially, a continuous variable (fractional shortening or left ventricular systolic function score), gender, and the interaction were included as independent variables. In both cases the interaction was non-significant and the model was reconstructed omitting that term. In a subsequent analysis relative wall thickness was added to these models.

\section{Results}

Women were older than their male counterparts (79 (9) $v 75$ (11) years, $P=0.002)$ but had a similar prevalence of congestive heart failure, syncope, and atrial fibrillation (table 2).
There were also no differences in New York Heart Association symptom classification between men and women. However, a more detailed 100 point score based on nine activities of daily living found that women scored lower in overall functional status. This difference persisted after adjustment for age. Women were more likely than men to have difficulty walking indoors, walking several blocks, walking one block, performing errands, driving, or performing vigorous activity, whereas there were no differences between men and women in the ability to care for themselves, move in and out of bed, or do housework. Thirty day mortality after balloon dilatation of the aortic valve tended to be higher in men $(12 \%)$ than in women $(5 \%)$, with a $P$ value of $0.06(0.60$ in those without wall motion abnormalities (table 2)).

Both Doppler echocardiographics and catheterisation measurements of peak resistance and aortic valve area index showed a similar severity of stenosis in men and women (table 3). Catheterisation also showed higher peak and mean gradients in women than in men. There were no significant differences in the prevalence or severity of mitral or aortic regurgitation or in left ventricular outflow tract velocity between the two sexes.

\section{LEFT VENTRICULAR SIZE AND HYPERTROPHY GEOMETRY}

Because of the marked difference in body size between men and women (table 2) all measurements were normalised to body surface area. After normalisation, women showed significantly greater septal and posterior wall

Table 3 Aortic valve variables

\begin{tabular}{|c|c|c|c|c|c|c|}
\hline & \multicolumn{3}{|l|}{ All patients } & \multicolumn{3}{|c|}{ Patients with wall motion abnormalities } \\
\hline & $\operatorname{Men}(n=92)$ & Women $(n=140)$ & PValue & $\operatorname{Men}(n=61)$ & Women $(n=108)$ & P Value \\
\hline \multicolumn{7}{|l|}{ Echo Doppler data: } \\
\hline velocity $(\mathrm{m} / \mathrm{s})$ & $0.80(0.23)(\mathrm{n}=72)$ & $0.87(0.24)(n=109)$ & 0.07 & $0.83(0 \cdot 25)(\mathrm{n}=47)$ & $0.91(0.24)(n=84)$ & 0.06 \\
\hline \multicolumn{7}{|l|}{$\begin{array}{l}\text { Peak aortc velocity }(\mathrm{m} / \mathrm{s}) \\
\text { Mean aortic gradient }\end{array}$} \\
\hline $\begin{array}{l}\text { Mean aortic gradient } \\
(\mathrm{mm} \mathrm{Hg})\end{array}$ & $48(18)(n=86)$ & $53(19)(\mathrm{n}=130)$ & 0.06 & $51(18)(\mathrm{n}=56)$ & $54(20)(n=100)$ & 0.47 \\
\hline Valve area $\left(\mathrm{cm}^{2}\right)$ & $0.63(0.20)(n=72)$ & $0.58(0 \cdot 24)(n=109)$ & $0 \cdot 14$ & $0.66(0.19)(n=46)$ & $0.61(0.25)(n=83)$ & $0 \cdot 21$ \\
\hline Valve area index $\left(\mathrm{cm}^{2} / \mathrm{m}^{2}\right)$ & $0.34(0.11)(\mathrm{n}=71)$ & $0.37(0.16)(\mathrm{n}=108)$ & 0.21 & $0.35(0.10)(n=45)$ & $0.39(0.17)(\mathrm{n}=82)$ & $0 \cdot 14$ \\
\hline Peak valve resistance & $1.79(0.79)(\mathrm{n}=68)$ & $2.04(0.95)(\mathrm{n}=104)$ & 0.08 & $1.69(0.75)(\mathrm{n}=43)$ & $1.93(0.85)(\mathrm{n}=79)$ & 0.13 \\
\hline \multicolumn{7}{|l|}{ Aortic regurgitation (echo)\%: } \\
\hline None & 25 & 24 & & 28 & 21 & \\
\hline Mild & 57 & 58 & & 56 & 58 & \\
\hline Moderate & 18 & 19 & & 16 & 20 & \\
\hline \multicolumn{7}{|l|}{ Catheterisation: } \\
\hline Peak gradient $(\mathrm{mm} \mathrm{Hg})$ & $63(22)(n=92)$ & $74(30)(n=138)$ & 0.002 & $65(22)(n=61)$ & $75(32)(n=107)$ & 0.01 \\
\hline Mean gradient (mm Hg) & $54(18)(\mathrm{n}=90)$ & $61(21)(n=138)$ & 0.01 & $57(18)(n=59)$ & $63(22)(n=106)$ & $0 \cdot 07$ \\
\hline Valve area $\left(\mathrm{cm}^{2}\right)$ & $0.56(0.18)(n=91)$ & $0.49(0 \cdot 20)(\mathrm{n}=138)$ & $0 \cdot 01$ & $0.57(0 \cdot 17)(n=60)$ & $0.50(0.21)(n=106)$ & 0.04 \\
\hline Valve area index $\left(\mathrm{cm}^{2} / \mathrm{m}^{2}\right)$ & $0.30(0.09)(\mathrm{n}=90)$ & $0.31(0.13)(n=136)$ & 0.53 & $0.30(0.09)(\mathrm{n}=59)$ & $0.31(0.14)(\mathrm{n}=104)$ & 0.50 \\
\hline
\end{tabular}


Table 4 Left ventricular size and hypertrophy: uncorrected

\begin{tabular}{|c|c|c|c|c|c|c|}
\hline & \multicolumn{3}{|l|}{ All patients } & \multicolumn{3}{|c|}{ Excluding patients with wall motion abnormalities } \\
\hline & $\operatorname{Men}(n=92)$ & Women $(n=140)$ & PValue & $\operatorname{Men}(n=61)$ & Women $(n=108)$ & $P$ Value \\
\hline Septal thickness (mm) & $13.4(3.0)(n=76)$ & $14.0(3.5)(n=113)$ & $0 \cdot 18$ & $13.7(2 \cdot 8)(\mathrm{n}=52)$ & $14 \cdot 4(3.6)(n=86)$ & $0 \cdot 20$ \\
\hline \multirow{5}{*}{$\begin{array}{l}\text { Cavity diameter (mm): } \\
\text { Diastole } \\
\text { Systole } \\
\text { Relative wall thickness } \\
\text { LV mass (g) }\end{array}$} & & & & & & \\
\hline & $52 \cdot 5(8 \cdot 3)(n=78)$ & $46 \cdot 6(8 \cdot 1)(n=119)$ & $<0.0001$ & $51 \cdot 3(8 \cdot 4)(\mathrm{n}=52)$ & $45.8(8.0)(n=90)$ & 0.0002 \\
\hline & $38 \cdot 2(10 \cdot 3)(\mathrm{n}=71)$ & $32 \cdot 1(9 \cdot 8)(\mathrm{n}=102)$ & 0.0001 & $35.6(9.9)(\mathrm{n}=50)$ & $30.7(9 \cdot 7)(\mathrm{n}=77)$ & 0.006 \\
\hline & $0.50(0 \cdot 15)(n=76)$ & $0.60(0 \cdot 20)(\mathrm{n}=117)$ & 0.0002 & $0.51(0.16)(\mathrm{n}=51)$ & $0.63(0.21)(\mathrm{n}=89)$ & 0.0005 \\
\hline & $294(94)(n=75)$ & $264(89)(n=112)$ & 0.03 & $290(88)(n=51)$ & $267(89)(n=85)$ & $0 \cdot 14$ \\
\hline
\end{tabular}

Relative wall thickness was calculated as two times posterior wall thickness divided by cavity diameter, with all measurements taken at end diastole.

Table 5 Left ventricular size and hypertrophy indexed to body surface area

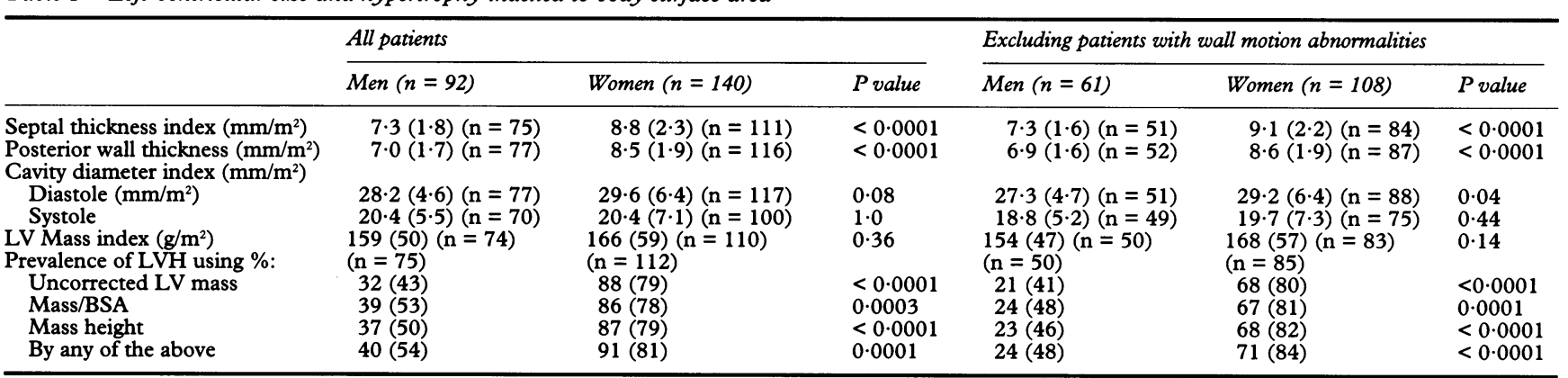

thicknesses but similar left ventricular cavity size at both end diastole and end systole (tables 4 and 5). This translated into a significantly higher relative wall thickness $(h / R)$ of 0.60 in women compared with 0.50 in men, and describes a more marked concentric pattern of hypertrophy. Although left ventricular mass index was similar in men and women $\left(159(50) v 166(59) \mathrm{g} / \mathrm{m}^{2}\right)$, the prevalence of left ventricular hypertrophy was significantly greater in women than in men whether as uncorrected left ventricular mass or mass normalised to body surface area or height (figure). The average prevalence of hypertrophy by these three methods was $49 \%$ in men as compared to $79 \%$ in women (table 5 ).

The associations between gender, left ventricular chamber geometry, and hypertrophy were further examined with multiple logistic regression models adjusting for age, functional status, fractional shortening, and left ventricular peak systolic pressure. Gender was independently associated with hypertrophy in all three models $(P \leqslant 0.002)$. Similarly a linear regression model was constructed using relative wall thickness rather than hypertrophy as the dependent variable. Relative wall thickness was chosen as a measure of ventricular geometry in addition to hypertrophy, which has the additional advantage of eliminating the use of cut off points in the definition of hypertrophy. Gender was independently related to relative wall thickness $(P=0.02)$ for all patients; $P=0.03$ for those without wall motion abnormalities) after adjusting for the other four covariates. In this model, left ventricular peak systolic pressure was also associated with relative wall thickness $(P=$ 0.001 for all patients; $P=0.002$ for those without wall motion abnormalities).

\section{LEFT VENTRICULAR FUNCTION}

Heart rates were similar in men and women (table 6). Cardiac index tended to be slightly higher in women at $2.5(0.8)$ v $2.3(0.6)$ $1 / \mathrm{min} / \mathrm{m},{ }^{2} \mathbf{P}=0.01$. Left ventricular peak systolic pressure was higher in women at 211 (36) $\mathrm{mm} \mathrm{Hg}$ as compared with men at 192 (35) $\mathrm{mm} \mathrm{Hg}, P=0.0001$. There was no difference in left ventricular end diastolic pressure, nor was there a significant difference in the prevalence of wall motion abnormalities.

Considering the population as a whole, all variables of left ventricular systolic function were higher in women than men including fractional shortening (32 (13) v 28 (12)\%) and echocardiographic ejection fraction (55 (14) $(\mathrm{n}=54) v 45(19) \%(\mathrm{n}=32), \mathrm{P}=0.01$. When fractional shortening was considered by category, $56 \%$ of men but only $37 \%$ of women had reduced shortening, while $25 \%$ of men and $35 \%$ of women had normal fractional shortening, $P=0.02$. In contrast, no differences were noted in these indexes of systolic function when comparing only those without regional wall motion abnormalities. In addition, overall left ventricular function judged echocardiographically showed that $58 \%$ of women had normal or enhanced function compared with $36 \%$ of men, while severely reduced function was found in $20 \%$ of men but only $9 \%$ of women $(P=0.001$ for all patients; $P=0.02$ for those without wall motion abnormalities).

Though calculation of left ventricular wall stress was impossible in this population derived from a registry data base, the question of afterload negatively influencing systolic function is of potentially great importance. We therefore examined the relations between left ventricular peak systolic pressure and fractional shortening and peak pressure and left ventricular systolic function score, as rough estimates of the stress-shortening relation. In both cases the regression lines for the two genders had the same slope, however, in men the $y$ intercept was significantly lower than in women $(P<0.01$ for all patients; $P<0.05$ (unnormalised mass, mass divided by body surface area (BSA), and mas
divided by height). 
Table 6 Left ventricular function (mean (SD))

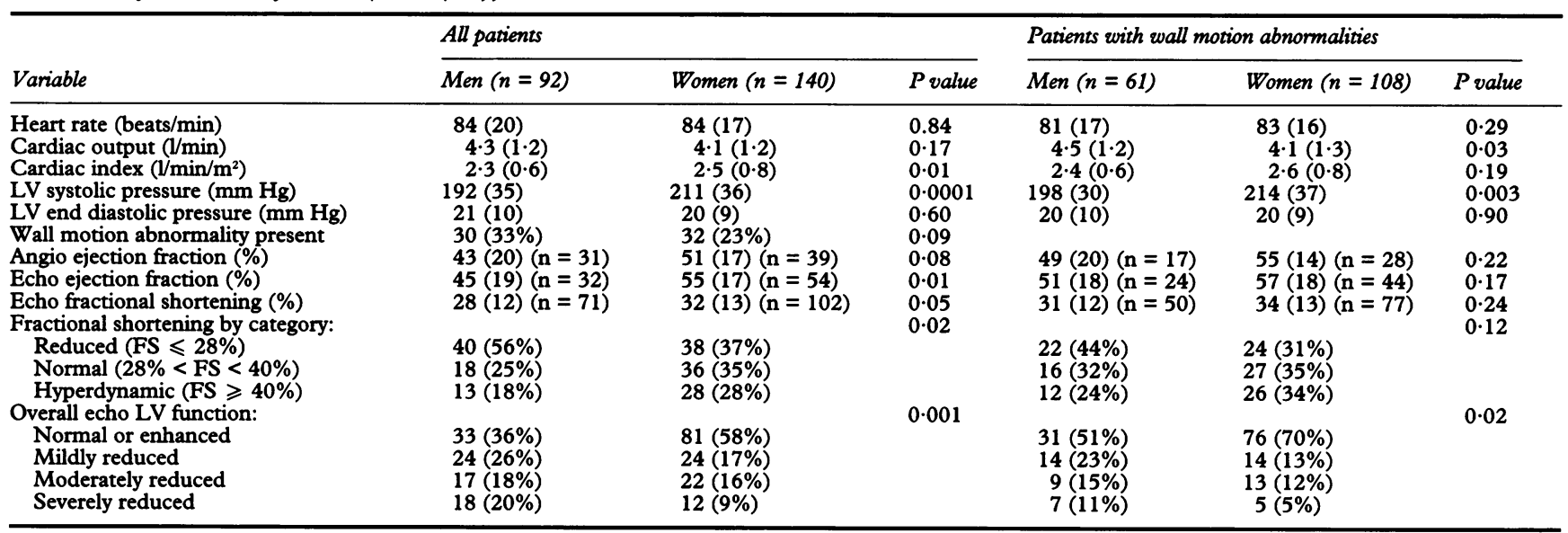

for those without wall motion abnormalities), describing a significant downward parallel shift of the relation and suggesting intrinsically impaired myocardial contractility. These gender differences were unchanged by adjustment for relative wall thickness. In the model including fractional shortening, relative wall thickness was independently associated with left ventricular systolic pressure $(P=0.003)$ for all patients; $P=0.01$ for those without wall motion abnormalities). However, relative wall thickness was not significant $(P=0.08$ for the entire group and for those without wall motion abnormalities) in the model including left ventricular systolic function.

\section{Discussion}

Although gender is known to influence cardiac size in the normal heart ${ }^{1-41011}$ little is known about possible influences in cardiac disease states. Within the limits of the highly selected patient population examined, the present study suggests that gender is associated with differences in left ventricular chamber remodelling in response to pressure overload caused by aortic stenosis, including left ventricular hypertrophy. Further, the preservation of left ventricular pump function seems to be different in men and women in a population with similarly stenotic valves, with regional wall motion abnormalities significantly impairing function in men, despite the exclusion of patients with severe epicardial coronary disease. While these differences might be explained by differences in the severity of pressure overload, men and women had remarkably similar aortic valve area indices. Although advanced age has been suggested as a limiting factor in the hypertrophic response to aortic stenosis, the women studied were actually older than the men and age did not affect the gender-hypertrophy relation. We found a higher relative wall thickness $(h / R)$ in women; this is a measure of both ventricular shape and of hypertrophy that is independent of the sex specific, population derived cutoffs used for normal left ventricular mass. Finally, after adjusting for age, functional status, fractional shortening, and left ventricular systolic pressure, gender was independently associ- ated with both the presence of hypertrophy and relative wall thickness.

Studies of the natural history of heart disease in humans suggest that gender is an important determinant of outcome, although the direction may vary with the disease. Women seem to have a better prognosis in hypertension, yet a worse prognosis after myocardial infarction. ${ }^{19}$ Gender differences in cardiac function are even less well explored. Several studies in rats have documented malefemale differences in myocardial function and biochemistry which can be altered by castration and/or hormone replacement, confirming that gender may be an important cardiac modulator. ${ }^{20-22}$ Female rats demonstrate left ventricular hypertrophy in response to exercise training while males do not. ${ }^{12}$ In humans, gender differences have been noted in some aspects of cardiac physiology such as cardiac response to exercise and basal adrenergic tone $\mathrm{e}^{23-25}$ and women with hypertension display a higher prevalence of hypertrophy than men with hypertension. ${ }^{56}$ In addition, a syndrome of hypertensive hypertrophic heart disease characterised by severe concentric hypertrophy, supranormal systolic function, and impaired diastolic function occurs much more commonly in women than in men. ${ }^{26}$ Finally, and most germane, Carroll et al have reported higher left ventricular systolic pressures and fractional shortening in elderly women with aortic stenosis than in men. ${ }^{7}$ Gender differences in aortic stenosis have also been reported by Villari et $a l^{8}$ and Aurigemma et $a l^{9}$ in smaller patient populations.

Abnormal systolic ejection patterns and even outflow tract gradients have been noted in elderly patients, especially women, even in the absence of hypertrophic cardiomyopathy. ${ }^{26}$ Such a flow pattern, if severe enough to cause an intracavitary gradient, could be an additional stimulus to hypertrophy in women, beyond that provided by their aortic stenosis. However, the Doppler data show no significant differences in outflow tract velocity, thereby excluding the possible contribution of an intracavitary gradient to the degree of pressure overload seen by the left ventricle.

The process of hypertrophy is thought to be a compensatory one - an attempt to normalise 
increased afterload. The lower relative wall thickness and prevalence of hypertrophy in men, despite similar valve areas, suggests that this process may be more commonly "inadequate" in men. Whereas women did have a higher peak left ventricular pressure, this may have been a reflection of better preserved systolic function. Other data also suggest that the excess afterload was better compensated in women: they had a higher cardiac index, fractional shortening, ejection fraction, and overall left ventricular function classification than did men.

The possible causes of the different remodelling and function can only be speculated upon. Perhaps the normally smaller female heart permits greater hypertrophy, and therefore better compensation, to occur. The normal female heart hypertrophies with age, in contrast to the male heart, ${ }^{3}$ perhaps in response to decreasing oestrogen levels after the menopause. ${ }^{27}{ }^{28}$ Ischaemia is known to occur as myocardial hypertrophy exceeds vascular growth and has been implicated in reduced ventricular function in hypertrophy. Though this vascular-myocardial mismatch might be expected to be most pronounced in the more hypertrophied hearts (that is, those of women) regional wall motion abnormalities tended to be more common in men and seemed to account for most, if not all of the observed difference in left ventricular function.

Despite better pump function, the women had a worse overall functional status score. This seemingly paradoxical finding may be partially explained in several ways. The women were older than the men, and might therefore be expected to be more frail and less independent. The higher relative wall thickness in women, though it is a compensatory response that normalises afterload, might also result in a greater degree of diastolic dysfunction. Our data also cannot address the possibility of either diastolic abnormalities or greater exercise intolerance in women. Interestingly, the pattern of worse clinical characteristics yet better angiographic measures of left ventricular function in women has been noted in several earlier studies, including patients undergoing coronary artery bypass grafting. ${ }^{29}$

Because patients with severe coronary artery disease, or severe aortic or mitral regurgitation were excluded, the present study does not contend with the possible effects of such concomitant conditions. The similarity in prevalence of left ventricular hypertrophy in the population as a whole and in the subgroup analysis of those without regional wall motion abnormalities suggests that geometric remodelling was not significantly affected by ischaemia, although overall left ventricular function was impaired. Finally, no data are available on the duration of aortic stenosis or the presence of coexisting hypertension, both factors which may affect the extent of hypertrophy. This last point is particularly important as we cannot exclude possible differences in the natural history of aortic stenosis between men and women or in the point at which they come to medical attention.

Though a retrospective survey of a previously defined study population allows collection of a sample that is large enough to address questions of differences associated with gender, it creates some constraints and limitations. The population studied was limited to those symptomatic patients with isolated aortic stenosis who had balloon dilatation of the aortic valve. Thus it is possible that gender-based selection bias in referral for balloon dilatation such as has been reported for coronary angiography and bypass surgery, may have affected our patient population. ${ }^{30-32}$ However, if this were true, one would expect the female patients to be "sicker", to have more advanced disease, or to have a worse outcome: there were no such findings. It is also quite possible that healthy men were referred to cardiac surgery more often than healthy women, thus selecting a population of "sicker" men to undergo balloon dilatation of the aortic valve. This influence of either selection bias on our results cannot be readily excluded.

The slight female preponderance among our population may also be due to such gender bias, but is more likely to be the result of the tendency to refer older patients for balloon dilatation. An additional explanation of the gender distribution may be found in our exclusion of any patient with coronary disease: this excluded a greater percentage of men than women.

All data were collected by highly experienced echocardiographers who met to agree upon strict criteria for echocardiographic measurement and interpretation. While intra and inter observer variability were not recorded, there is no reason to suspect systematic error, so that variability in measurements between centres should not substantially affect overall results in this large population. Left ventricular mass was assessed echocardiographically, using only short axis dimensions, because neither cross sectional echocardiograms nor angiographic mass were included in registry data. Use of relative wall thickness as an indicator of chamber geometry helps to mitigate this limitation. The systolic left ventricular dimensions needed to estimate left ventricular wall stress and Doppler inflow velocities needed to assess diastolic function were not recorded as part of registry data and are therefore not available.

For variables related to body size, both uncorrected and indexed values are reported. Dividing by body surface area dramatically changes the $t$ test results for some comparisons, but does not affect others, such as relative wall thickness. Uncorrected septal thickness and posterior wall thickness are not significantly different between men and women; however, the indexed values are larger in women $(P<0.0001)$. Conversely, uncorrected cavity diameters in both diastole and systole are significantly different in men and women, but comparisons of the indexed values are not significant. Because body 
surface area is strongly associated with gender, it is difficult to discern whether the true gender relations are uncovered, induced, or masked by indexing.

In summary, among elderly patients undergoing balloon dilatation for symptomatic isolated aortic stenosis, women had greater functional impairment and were more likely to have left ventricular hypertrophy and altered left ventricular geometry (highly relative wall thickness) than men. Left ventricular systolic pressure was higher in women, and men were more likely to have impaired global or regional ejection performance.

The clinical implications of the association of these differences with gender are unclear. Since published reports suggest that patients with aortic stenosis who have adequate compensatory hypertrophy and preserved pump function have a better prognosis, one might postulate that women with aortic stenosis should fare better than men, despite their poorer functional status. In contrast, a greater extent of left ventricular hypertrophy in hypertension has been associated with an adverse prognosis for both men and women. ${ }^{33} 34$ In either case, our cross sectional data cannot directly address the question of a gender difference in the natural history of aortic stenosis; additional studies would be necessary to confirm such an hypothesis.

Our study showed that in this selected population of elderly patients with isolated aortic stenosis, men and women demonstrate different hypertrophic and functional responses to left ventricular pressure overload. Gender should be further evaluated as a possible, albeit previously neglected, determinant of cardiac adaptation in aortic stenosis before extrapolation to other populations.

We thank Iris Wasserman and Gail Traylor for their excellent secretarial support.

1 Levy D, Savage DD, Garrison RJ, Anderson KM, Kannel WB, Castelli WP. Echocardiographic criteria for left ventricular hypertrophy: The Framingham Heart Study. Am $\mathcal{f}$ Cardiol 1987;59:956-60.

2 Devereux RB. Detection of left ventricular hypertrophy by M-mode echocardiography. Anatomic validation, standardization, and comparison to other methods. Hypertension 1987;9(suppl II):9-26

3 Dannenberg AL, Levy D, Garrison RJ. Impact of age on echocardiographic left ventricular mass in a healthy population (The Framingham Study). Am f Cardiol 1989; ulation (T:1066-8

4 Lauer MS, Anderson KM, Levy D. Influence of contemporary versus 30 -year blood pressure levels on left venporary versus 30-year blood pressure levels on left ventricular mass and geometry: The Framin

5 Devereux RB, Pickering TG, Alderman MH, Chien S, Borer JS, Laragh JH. Left ventricular hypertrophy in hypertension prevalence and relationship to pathophysiologic variables. Hypertension 1987;9(suppl II): $53-60$.

6 Liebson PR, Grandits G, Prineas R, Dianzumba S, Flack $\mathrm{JM}$, Cutler JA, et al. Echocardiographic correlates of left ventricular structure among 844 mildly hypertensive men and women in the treatment of mild hypertension study (TOMHS). Circulation 1993;87:476-86.

7 Carroll JD, Carroll EP, Feldman T, Ward DM, Lang RM, McGaughey D, Karp RB. Sex-associated differences in left ventricular function in aortic stenosis of the elderly. Circulation 1992;96:1099-107.
8 Villari B, Hess OM, Campbell SE, Krayenbuehl HP. Sexdependent response of the left ventricle to aortic valve stenosis: influence of the collagen network [abstr]. Circulation 1992;86:I538.

9 Aurigemma I: GP, Silver KH, McLaughlin M, Mauser J, Gaasch WH. Impact of chamber geometry and gender on left ventricular systolic function in patients $>60$ years on left ventricular systolic function in patients $>60$ years of age with aortic stenosis. Am f Cardiol 1994:74:794-8.
Schaible TF, Scheuer J. Comparison of heart function in Schaible TF, Scheuer J. Comparison of heart function in
male and female rats. Basic Res Cardiol 1984;79:402-12.

11 Shreiner DP, Weisfeldt ML, Shock NW. Effects of age, sex and breeding status of the rat heart. Am $\mathcal{F}$ Physiol 1969;217:176-80.

12 Schaible TF, Penpargkul S, Scheuer J. Cardiac responses to exercise training in male and female rats. 7 App Physiol Respirat Environ Exercise Physiol 1981;50:112-7.

13 Pfeffer J, Pfeffer M, Fletcher P, Braunwald E. Alterations of cardiac performance in rats with established spontaneous hypertension. Am $\mathcal{F}$ Cardiol 1979;44:994-8.

14 Jette AM, Davies AR, Cleary PD, Calkins DR, Rubenstein LV, Fink A, et al. The functional status questionnaire: reliability and validity when used in primary care. $\mathcal{F}$ Gen reliability and validity when $1986 ; 1: 143-9$.

15 Sahn DJ, DeMaria A, Kisslo J, Weyman A. The committee on M-mode standardization of the American Society tee on M-mode standardization of the American Society of Echocardiography: recommendations regarding quantitation in M-mode echocardiography: results of a survey
of echocardiographic measurements. Circulation 1978;

16 Devereux RB, Alonso DR, Lutas EM, Gottlieb GJ, Campo E, Sachs I, et al. Echocardiographic assessment of left ventricular hypertrophy: Comparison to necropsy findings. Am $\mathcal{F}$ Cardiol 1986;57:450-8.

17 Pearlman AS. The use of Doppler in the evaluation of cardiac disorders and function. In Hurst JW, ed. The heart New York: McGraw-Hill, 1990;2039.

18 Snedecor GW, Cochran WG. Statistical methods. 6th ed. Iowa State University, 1967.

19 Douglas PS. Heart disease in women. Philadelphia: FA Davis, 1989.

20 Scheuer J, Malhotra A, Schaible TF, Capasso J. Effects of gonadectomy and hormonal replacement on rat hearts. Circ Res 1987;61:12-9.

21 Schaible TF, Malhotra A, Ciambrone G, Scheuer J. The effects of gonadectomy on left ventricular function and cardiac contractile proteins in male and female rats. Circ Res 1984;54:38-49.

22 Capasso JM, Remily RM, Smith RH, Sonnenblick EH. Sex differences in myocardial contractility in the rat. Basic Res Cardiol 1983;78:156-71.

23 Wagner JA, Horvath SM. Cardiovascular reactions to cold exposures differ with age and gender. $\mathcal{F}$ Appl Physiol 1985;58:187-92.

$24 \mathrm{Du}$ X, Dart AM, Riemersma RA, Oliver MF. Sex differences in presynaptic adrenergic inhibition of Norepinephrine release during normoxia and ischemia in the rat heart. Circ Res 1991;68:827-35.

25 Higginbotham MB, Morris KG, Coleman RE, Cobb FR. Sex-related differences in the normal cardiac response to upright exercise. Circulation 1984;70:357-60.

26 Topol EJ, Traill TA, Fortuin NJ. Hypertensive hypertrophic cardiomyopathy of the elderly. $N$ Engl $\mathcal{F}$ Med trophic cardiomyo

27 Cabral AM, Vasquez EC, Moyses MR, Antonio A. Sex hormones modulation of ventricular hypertrophy in sinoartic denervated rats Hypertension 1988:11(suppl I):93-7.

28 Fischer GM, Swain ML, Effect of sex hormones on blood pressure and vascular connective tissue in castrated and noncastrated male rats. Am $\mathcal{f}$ Physiol 1977;232 H617-21.

29 Davis KB. Coronary Artery Bypass Graft Surgery in Women. In Eaker ED, Packard B, Wenger NK, Clarkson TB, Tyroler HA, eds. Coronary heart disease in women. New York: Haymarket Doyma, 1987;

Tobin JN, Wassertheil-Smoller S, Wexler JP, Steingart RM, Budner N, Lense L, Wachspress J. Sex bias in considering coronary bypass surgery. Ann Int Med 1987;107:19-25.

31 Ayanian JZ, Epstein AM. Differences in the use of procedures between women and men hospitalized for corodures between women and men hospitalized for
nary heart disease. $N$ Engl $₹$ Med 1991;325:221-5.

32 Steingart RM, Packer M, Hamm P, Coglianese ME Gersh B, Geltman EM, et al. Sex differences in the management of coronary artery disease. $N$ Engl f Med 1991 325:226-30.

33 Levy D, Garrison RJ, Savage DD, Kannel WB, Castell WP. Prognostic implications of echocardiographically determined left ventricular mass in the Framingham Heart Study. N Engl F Med 1990:322:1561-6

34 Koren MJ, Devereux RB, Casale PN, Savage DD, Laragh $\mathrm{JH}$. Relation of left ventricular mass and geometry to morbidity and mortality in uncomplicated essential hypertension. Ann Intern Med 1991;114:345-52. 